\title{
Massive Hematemesis: An Uncommon Presentation of an Unusual Diagnosis
}

\author{
Rui Mendo Catarina Félix Pedro C. Figueiredo \\ Department of Gastroenterology, Centro Hospitalar de Lisboa Ocidental, Hospital de Egas Moniz, Lisbon, Portugal
}

\section{Keywords}

Gastrointestinal bleeding · Dieulafoy's lesion · Small-bowel diverticulosis

\section{Hematemeses massivas: Apresentação rara de um diagnóstico incomum}

\section{Palavras Chave}

Hemorragia gastrointestinal - Lesão de Dieulafoy ·

Diverticulose do intestino delgado

A 74-year-old male presented to the emergency department following several episodes of hematemesis and hematochezia. The patient was on dabigatran for chronic atrial fibrillation. Physical examination revealed pallor, tachycardia, and hypotension with a systolic blood pressure of $87 \mathrm{~mm} \mathrm{Hg}$. Laboratory blood tests showed a hemoglobin level of $8.8 \mathrm{~g} / \mathrm{dL}$, urea of 36 $\mathrm{mg} / \mathrm{dL}$, and creatinine of $1.06 \mathrm{mg} / \mathrm{dL}$. The patient responded to the initial resuscitative measures, requiring idarucizumab and 2 units of red blood cells, and underwent an upper gastrointestinal endoscopy that revealed

\section{KARGER}

E-Mail karger@karger.com www.karger.com/pjg
(C) 2019 Sociedade Portuguesa de Gastrenterologia

Published by S. Karger AG, Basel

Karger

Open access

This article is licensed under the Creative Commons AttributionNonCommercial-NoDerivatives 4.0 International License (CC BYNC-ND) (http://www.karger.com/Services/OpenAccessLicense). Usage and distribution for commercial purposes as well as any distribution of modified material requires written permission. fresh blood in the stomach and duodenum without signs of an active bleeding lesion. The patient subsequently experienced a second episode of hemodynamically significant hematemesis and hematochezia requiring additional transfusion support. Upper gastrointestinal endoscopy was repeated soon thereafter, but it was once again inconclusive. Ultimately, the patient developed shock, and a computed tomography (CT) angiography was performed, showing an actively bleeding jejunal lesion on the CT angiography (Fig. 1). The patient underwent a laparotomy that uncovered a diverticulum on the mesenteric border of the proximal jejunum, 30 $\mathrm{cm}$ distal to the ligament of Treitz, with an apparent intraluminal bleeding. There was rapid hemodynamic improvement after surgical resection (Fig. 2). Histopathology disclosed a pseudo-diverticulum with a dilated submucosal artery protruding through normal surrounding mucosa that ruptured into the intestinal lumen (Fig. 3), compatible with a Dieulafoy's lesion in a jejunal diverticulum.

Small-bowel diverticulosis is an uncommon condition, with an estimated incidence of $0.4-4.6 \%$ [1]. It is usually an asymptomatic condition, typically arising on the mesenteric border of the bowel [1]. Rarely, it can be 
Fig. 1. CT angiography showing an actively bleeding jejunal lesion (arrow).

Fig. 2. Jejunal diverticulum after surgical resection.
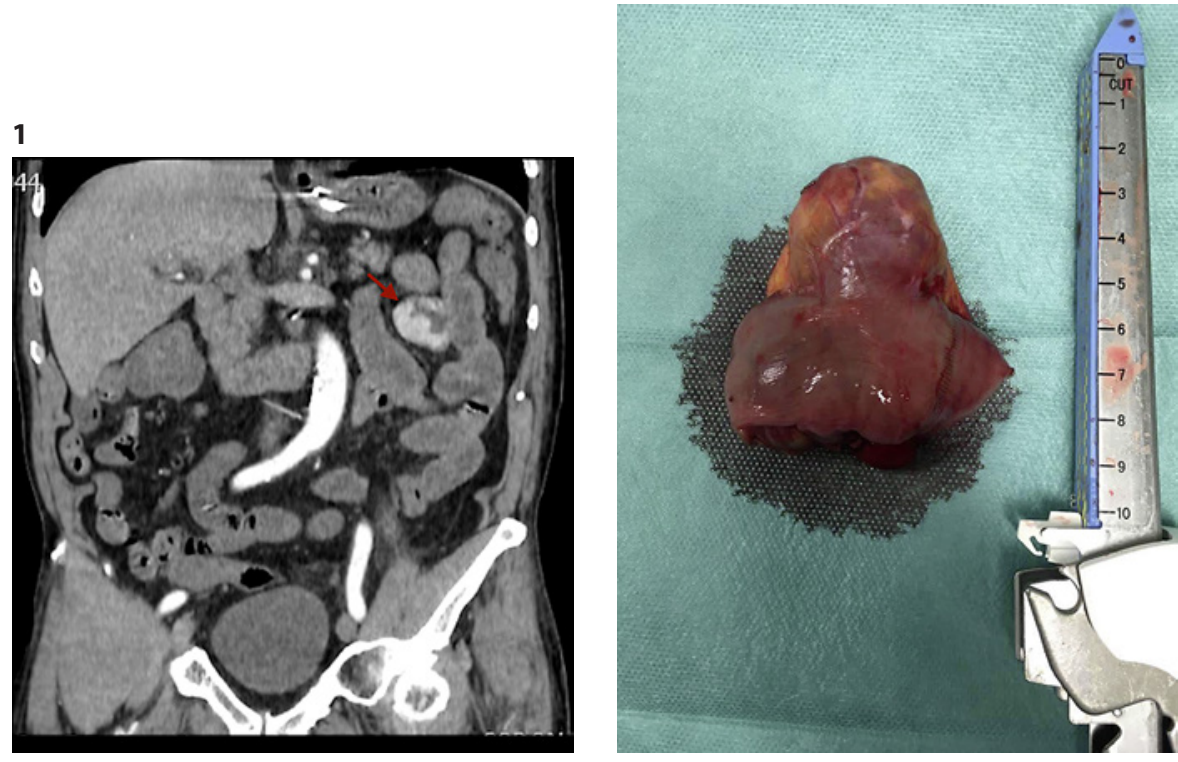

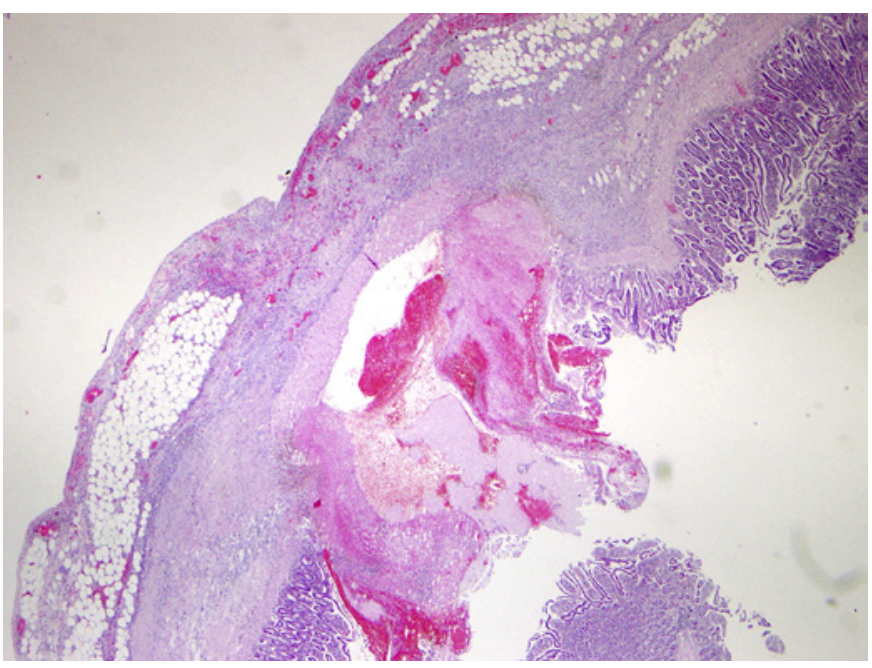

Fig. 3. Histopathology revealing a pseudo-diverticulum with a dilated submucosal artery protruding through normal surrounding mucosa, rupturing into the intestinal lumen.

associated with complications such as diverticulitis, perforation, and massive gastrointestinal bleeding (GIB) [1]. Delay in the diagnosis of massive GIB secondary to smallbowel diverticulosis is common. As a result, it is associated with significant morbidity and mortality. On the other hand, a Dieulafoy's lesion is frequently associated with massive GIB but is usually located in the stomach and, less frequently, in the duodenum, small bowel, and colon [2].

Unusual Presentation of Hematemesis
In this particular case, intermittent and hemodynamically significant hematemesis suggested an upper GIB arising from a Dieulafoy's lesion, but despite performing an upper endoscopy soon after the second episode, no bleeding site was found. Hence, a CT angiography was done and led to the diagnosis. As interventional radiology was unavailable, a surgical consultation was therefore obtained. Had we considered that hematemesis was a rare presentation of a small-bowel GIB, a push enteroscopy could have followed the second inconclusive upper endoscopy. However, the patient remained unstable after the CT findings, precluding another endoscopy.

We present this case not only due to the unusual presentation of hematemesis following a massive small-bowel bleeding but also due to the uncommon association between a Dieulafoy's lesion and a jejunal diverticulum.

\section{Statement of Ethics}

The authors have no ethical conflicts to disclose.

\section{Disclosure Statement}

The authors declare no conflicts of interest.

Funding Sources

The authors have no funding sources to declare.

GE Port J Gastroenterol 2020;27:68-70 


\section{Author Contributions}

Rui Mendo: acquisition of data; analysis and interpretation of data; drafting of the manuscript.

Catarina Félix: acquisition of data; revision of the manuscript for important intellectual content.

Pedro C. Figueiredo: critical revision of the manuscript for important intellectual content.
References tens D. Rare Jejunal Diverticular Bleeding. ACG Case Rep J. 2016 Oct;3(4):e146.

2 Dulic-Lakovic E, Dulic M, Hubner D, Fuchssteiner H, Pachofszky T, Stadler B, et al.; Austrian Dieulafoy-bleeding Study Group. Bleeding Dieulafoy lesions of the small bowel: a systematic study on the epidemiology and efficacy of enteroscopic treatment. Gastrointest Endosc. 2011 Sep;74(3):573-80. 